\title{
THE UNBOOKED MATERNITY PATIENT IN AN ACADEMIC HOSPITAL IN DURBAN
}

\author{
R. Gcaba and H.B. Brookes
}

\begin{abstract}
This paper examines the unboaked maternity patient in an academic hospital in Durban, Natal. This hospital is the biggest hospital serving the underprivileged population of this area. Of the 16000 annual deliveries in this hospital, about $12 \%$ are unbooked patients.

The health belief model of Rosenstock, as interpreted by Mikhail, and Cax's interaction model of client health behaviour were used as a theoretical framework for this research. A gualitative case study methodology was undertaken and semi-structured interviews were conducted with unboaked mothers who had utilized appropriate health services in a previous pregnancy. The aim of such interviews was to explore reasons given by mothers for non-use of facilities in the current pregnancy. The basic trends reflected in the findings regarding non-utilization of health services were client instability, health service failure and socio-cultural constraints. The study is innovative and addresses the problem from a social-cultural and midwifery perspective.
\end{abstract}

\section{NTRODUCTION}

The study focuses on the circumstances surrounding the 'unbooked' maternity patient and the setting is a referral hospital for the greater Durban area, Natal and KwaZulu. It serves a population of approximately two million people in the Durban area, is the biggest hospital in Natal/KwaZulu and has a total of 1971 beds of which 334 are for maternity patients.

Studies previously carried out in this institution have indicated that unbooked patients deliver more low birth weight infants, have a higher perinatal mortality and born-before-arrival (B.B.A.) rate than mothers who are booked patients. Larsen and Van Middelkoop (1982) observed that $35 \%$ of the women delivering in this hospital were unbooked, and Loening and Broughton (1984) noted that $19.4 \%$ of the neonates in the neonatal nursery of the hospital were delivered of unbooked mothers. In 1989, this institution had 14228 deliveries of which 1670 were unbooked. In order to determine the feasibility of the present study, a statistical analysis of the labour ward admission was done in July 1990 which reflected that $10.9 \%$ of patients were unbooked.

Surprisingly, there is no real agreement among authorities as to the definition of an 'unbooked mother'. For the purpose of this study, an 'unbooked patient' is a woman who has not received adequate antenatal screening in the hospital antenatal clinic or in any of the peripheral health centres, other hospitals, or by private medical practitioners. 'Adequate antenatal care' implies adequate antenatal screening which in turn includes careful history taking, routine screening on blood tests, full physical examination of the woman, assessment of the period of gestation, routine urine tests, weight and blood pressure estimation. This operational definition is derived from Green-Thompson (1990).

\section{LITERATURE REVIEW}

Comparative studies of booked and unbooked patients demonstrate that the unbooked patient is a woman with limited resources and that pregnancy outcome from unbooked clients is often high risk (Loening and Broughton 1985, Pattison and Rossouw 1985).

Important demographic factors including advancing parity, single parenthood, poor relationship with the father of the child, lack of financial support and accommodation were reflected in the literature as contributory factors to women becoming unbooked. (Ryan et al 1980, Larsen and Van Middelkoop 1982, Cox 1982, Hamilton et al 1987). Findings in regard to age were not consistent and education levels appeared not to be significant (Pattison and Rossouw 1985). Socio-demographic factors can be seen to influence booking status and health related behaviour as suggested by Larsen (1978), Cox (1982), Larsen et al (1983),
Pattison and Rossouw (1985), Galway et al (1987) and McDonald and Cobum (1988).

Distance from health services, poor attitudes and communication, as well as a wide social gap between health service personnel and health consumers, inconvenient clinic hours and ineffective planning of health services, all contribute to women becoming unbooked. (Ademuwagun 1972, Larsen et al 1983, and Galway, Wolff and Siurgis 1987).

\section{SOCIO-CULTURAL FACTORS}

Conco (1972) gave an interesting account of how a woman who considers herself to be having 'ipuleti' (a blanket term for all obstetric complications such as pregnancy induced hypertension, antepartum haemorrhage, posi-partum haemorrhage, cephalo-pelvic disproportion, puerperal sepsis, still births and neonatal deaths and a wide range of unexplained maternal fetal and neonatal complications) as diagnosed by a family member or traditional healer, would start antenatal clinic altendance early to see if the medical practitioner or nurse at the clinic diagnoses her problem or not. If they refute the existence of ipuleti as unscientific and unfounded, the patient may be so discouraged and so distrustful of the medical practitioner or nurse that she may never retum to the health service. This negative health care experience thus influences her health related behaviour (HRB) and this reflects Cox's (1982) notion that negative and positive health care experiences influence HRB. Conco $(1972,295)$ further explains that in traditional Zulu society normal labour was usually managed by family members; however, if there were problems a community consultant was summoned and if the consultant failed, the woman would then be transferred to the nearest health service. He summarised the referral system as follows:

1st level : family management, usually an elderly male or female

2nd level : skilled community consultant e.g. herbalist or traditional doctor or traditional birth attendant (T.B.A.) 
3rd level : clinic, hospital or medical practitioner.

\section{TIIEORETICAL FRAMEWORK}

The health belief model (HBM) of Rosenstock as interpreted by Mikhail and Cox's interaction model of client health behaviour guided this study. Rosenstock's model postulates that a client's health related behaviour (HRB) is influenced by the degree of perceived threat to health, susceptibility to risk, and perceived benefits as well as the individual's motivation to seek medical help (Mikhail 1981). According to the Zulu referral system as explained by Conco (1972) as long as there is no perceived threat, labour may be conveniently planned to be managed at home by family members. Once a threatening situation occurs, help is sought from outside the family but still within the boundaries of the community and within the same culture. When the threatening situation becomes severe, help is sought from outside these parameters.

The HBM suggests that utilisation of health services is directly related to the individual's perception of the cost and benefits from health related behaviour (HRB). Cost and benefit are evaluated in terms of money, time, convenience and efficancy of the health service as perceived by the patient.

Cox (1982) argues that HRB is influenced by some major variables such as elements of client singularity (or individuality), elements of client and professional worker's interaction and elements of health outcome.

The health professional gives information to the client regarding the seriousness of the health problem, limitations imposed upon the client, and actions that the client needs to take in order to limit the negative effects of the health problem. The health worker must provide effective support, coupled with cognitive awareness of the health problem to enhance the client's accurate interpretation and perception of the health problem. The client expects to be included in decision-making regarding her health status. The HBM postulates that where there is greater need for the professional technical expertise during the acute phase of patient intervention, the bulk of decision-making falls on the professional.

\section{TIIE RESEARCI QUESTION}

The research question revolved around reasons why previously booked patients become unbooked in a subsequent pregnancy. Could there be some health personnel practices that are unacceptable to the patients? The previously booked patient must be seen as a "converted" patient. If she then becomes unbooked in a subsequent pregnancy, this implies that the initial motivation to book has not been sustained.
The aim of the sludy therefore was to determine factors that influence poor utilization of prenatal services. Current studies exploring reasons for failure to attend health services have been comparative and centred around a medical perspective. The researcher hoped to discover other aspects that would reveal a nursing and/or a socio-medical dimension.

\section{RESEARCII OBJECTIVES}

\section{To determine:}

1) Reasons pertaining to the previously booked or health service delivery patient becoming unbooked in a subsequent pregnancy.

2) Factors related to the perception of pregnancy as a normal phenomenon leading to a disregard of the potential associated risks.

\section{METIIODOLOGY}

Case studies using partially structured interviews were carried out solely by the researcher. In-depth information regarding the dynamics related to the unbooked mother and the role of the significant other were obtained. Ten women were interviewed at length. All had the purpose of the study explained to them and agreed to the interview.

Data gathered were predominantly qualitative in nature but some aspects such as demographic variables had to be quantified for clarity.

\section{SAMPLE SELECTION}

Qualifying criteria for respondents were that they had to be multiparous patients who had previously utilised a health service for childbirth during pregnancy and/or delivery and puerperium but were unbooked in the present pregnancy. Respondents were selected from the labour ward admission book and followed in the post partum wards. Where it was inadvisable to interview the selected subject, the next client was interviewed.

\section{PILOT STUDY}

A pilot study was carried out on two respondents who fitted the sample criteria. A partially structured interview schedule was tried out and this method was found to be suitable as was the interview schedule. Notes were not written at the bedside initially; however as this became time-consuming it was abandoned and notes were written during the process of interviewing in the main study. The interview guide was not changed.

\section{DATA COLLECTION}

Data collection was carried out from June to November 1990 . All handwritten notes were documented following a pre-planned typed interview guide. The collection of data for the pilot study was carried out over one month. Interviews lasted from one to two hours and were carried out in the post-natal wards within the first week of delivery. The number of interviews per client ranged between one and three. Those having more than one interview had either an additional interview at home or had extra interviews if they were emotionally upset during the first or second interview. The same interview schedule and guide were used for all the interviews.

\section{RELIABILITY}

Reliability was found difficult to confirm; it was noted that the information that had been given in hospital by one respondent conflicted with the information that was obtained when a home visit by the researcher was made. Information given in hospital had been more socially acceptable than the real situation. The "ipuleti" concept explained by Conco (1972) was validated when one of the respondents was visited at her home. The information would not have been discovered if the home visit had not been carried out and this demonstrated that greater insight can be gained by doing further qualitative studies in the real situation.

\section{DATA ANALYSIS AND DISCUSSION OF FINDINGS}

\section{Socio Demographic Factors}

\section{Age}

The ages of the unbooked mothers rangec between 19 years and 41 years. The mean age was 26.7 years. There were two respondents in a high risk age group, both women being over the age of 35 years.

\section{Parity}

Parity ranged between 2 and 5 , the majority being para 2 . There was one respondent in the high risk grande multiparous group. This patient had a problem of early rupture of membranes and urinary tract infection.

\section{Relationship with Present Consort}

Only four of the ten respondents reported stable relationships with the father of the child. This information supports findings noted by Larsen and Van Middelkoop (1982) and Pattison and Rossouw (1987). Only two of the respondents had the same consort for all their children.

\section{Financial Support}

According to the South African Institute of Race Relations (1990) the household subsistence level (HSL) for an average African family of five in the Durban area at that time was R536,51. The household effective level (HEL) for the same size family was R804.77. In the light of this information only three respondents lived above the HSL and only two of these lived above the HEL.

\section{Stability of Accommodation}

Only four of the respondents had stable accommodation. Factors that appeared to influence instability of accommodation were life in informal settlements, political instability, 
change of employment and/or boyfriend and distance from health services. Scott-Samuel (1980) also noted that the unbooked mother often had unstable accommodation.

\section{Employment Status}

Only two women were employed. Four were employed casually and four were not employed.

\section{Level of Education}

According to the definition from Operation Upgrade (1991), literacy is defined as Standard Four level or more. The educational level of respondents ranged between illiteracy and Standard 8. There were four illiterate and six literate subjects. One of the subjects was able to read calendar months accurately to an extent that she was able to diagnose herself as post mature in a former pregnancy, yet she had never been to school and she had declared herself illiterate. Illiteracy appeared to relate to the woman's age. Three of the oldest women in the group (ages 29, 33 and 41 years) were illiterate. The two youngest in the group ( 19 and 20 years) had a Standard 8 education. None of the respondents had more than 12 years of schooling, which finding supports the report of St Clair et al (1989), stating that women who had less than 12 schooling years were underutilizers of prenatal services.

\section{RELIGIOUS AFFILIATION IN RELATION TO USE OF "ISIIILAMBEZO" AND/OR "ISIWASIIO"}

Out of three traditional religion affiliates, two used "isihlambezo", a herbal infusion sipped by a pregnant woman to assist her during pregnancy and confinement (Doke and Vilakazi $1972,317)$. One used neither "isihlambezo" nor "isiwasho", which is Holy water used by Zionist Spiritualists prepared by salt or ash added to water (Mabaso, 1989, 336). Four Christians used either "isihlambezo" or "isiwasho" or both. Four Zionists used "isiwasho". One woman could not use "isihlambezo" or "isiwasho" during pregnancy because she had kept her pregnancy a secret as she was a scholar but she used a herbal prepration during the puerperium. This aspect has not been found in the literature but was validated by Sithole (1990) who explained that a herbal preparation made from "ugobo", an oxytoxic plant was taken orally during puerperium to expel clots and products of conception.

\section{FAMILY FACTORS}

Three respondents had been advised by the mother or guardian to attend clinic during their previous first pregnancies. Two women had since moved from their homes and the decision not to attend clinic during the present pregnancy was entirely theirs. It is common practice in the Zulu-speaking society to have the first pregnancy under the care of an experienced woman who is trusted to make sound decisions. During the first pregnancy and delivery the nulliparous woman is usually taken to be a young inexperienced person who has not yet fully grown and is not considered able to make independent decisions during pregnancy and labour.

\section{APPLICATION OF TIIE IIEALTI BELIEF MODEL (IIBM)}

\section{Perceived Threat}

Interpretation of perceived threat was related to the informants' identification of danger signs in pregnancy and labour. Other important obstetric complications such as severe headache, epigastric pain, swelling of feet and legs were not perceived as threatening signs. One multiparous teenager said, "The last I remember about myself is that I had a severe headache and stomach ache at home. The next thing that happened is that I saw myself in hospital during visiting time. My uncle told me that I had been in hospital for two days and I had been cut. The size of the baby is incredibly small." She cried. The interview was closed. Another informant explained, "I had decided to attend antenatal clinic, however I was unfortunate all the way through. When I wanted to go to the nearest clinic, my friend told me that the nurses would scold me for attending late. I then decided to go to another clinic which was also not far from my home. When I got there I was told to come the following week because there had been a burglary at the clinic. When I got there a week later, I was told that they were not yet fully organised to see patients and I should come the following week. My neighbour who was sympathetic about my unsuccessful clinic visits gave me isihlambezo. I had a fit two days ago and gave birth to a dead baby. The time I spent trying to attend clinic was stressful and useless to me".

\section{IDENTIFICATION OF SEVERE IIEALTII PROBLEMS BY RESPONDENTS}

Lack of knowledge and/or insight into the danger signs during pregnancy resulted in taking action only to solve the problem at an advanced stage of the discase process. It was not until one of the informants had a fit that the family engaged in health related behaviour, yet the family had been with her when she had severely swollen legs and feet. Another informant did not interpret sluggish fetal movements as a serious problem. Two weeks later, she had an abruptio and delivered a macerated fetus. She thought that the maceration was due to the hot liquor which burnt the child in utero. These and other examples arc reflected in Table 1.

\section{PROVISION OF IIEALTII INFORMATION}

Respondents explained how they lacked information. They were not al ways told by the professionals why they were being transferred from one instilution to the other. When the baby was born, mothers intuitively understood that the baby had died because it had not cried at birth but they were not told the where the dead baby was. Most respondents were not involved in decision-making regarding funeral arrangements for the baby until they were discharged. Insufficient information was given and there was no opportunity to ask questions. One respondent who had given a consent for lubal ligation was worried for over 24 hours, not knowing whether she had been ligated or not.

\section{POLITICAL COMMUNITY DISRUPTION}

Health services which had previously rendered 24 hour services had been reduced to day services. Mobile health services were unable to get to some areas. Transport services had been disrupted because of bus boycolts.

\section{JOB INSECURITY}

Failure to discuss pregnancy with the employer to get time off to attend antenatal clinic for fear of losing the job, and failure of the clinic to render antenatal care after hours resulted in two respondents not booking.

\section{WOMEN'S PERCEPTION OF PREGNANCY}

Interpretation of pregnancy as a normal phenomenon was apparent in three respondents who did not book because they had considered their pregnancy to be normal. One respondent who had delivered a premature baby in the immediate previous pregnancy, had not considered that she could have a similar problem in the present pregnancy. She thought that she had outgrown that possibility, as she had been only 17 years of age when she had the first preterm baby. The second woman had not attended antenatal clinic because she had not noted any problem in her pregnancy until she started to bleed. Placental abruption was diagnosed in her pregnancy. The third woman had booked in the previous pregnancy because at that time she lived with her mother who had insisted that she attended clinic. She had not booked presently because she did not think she had a problem until she had a fit, an abruptio and a neonatal death. A home visit was done on the day that this informant had a cleansing ceremony for the negative outcome of her pregnancy. She explained that Zionist spiritualisi had said, "I have an ipuleti which I do not know how I got because I was healthy in my past pregnancy, and this baby is healthy as you can see", referring to her two-year old child from the previous boyfriend. She further explained that the Zionist spiritualist had said, "I got ipuleti when I changed from my mother's place to this place. I think my boyfriend's previous girlfriends were jealous of my pregnancy and they bewilched me." 
TABLE I

TYPE OF THREAT TO PREGNANCY IDENTIFIED BY RESPONDENTS

\begin{tabular}{|c|c|c|c|c|c|}
\hline TYPE OF THREAT & $\begin{array}{l}\text { MATEANAL IDENTI } \\
\text { FICATION } \\
\text { OF THREAT }\end{array}$ & $\begin{array}{l}\text { NO OF PA- } \\
\text { TIENTS }\end{array}$ & $\begin{array}{l}\text { OBSTETRIC } \\
\text { PROBLEM }\end{array}$ & FETAL OUTCOME & $\begin{array}{l}\text { BIRTH } \\
\text { WEIGHT }\end{array}$ \\
\hline Bleoding & Yes & 2 & $\begin{array}{l}\text { Abruptio } \\
\text { Abruptio }\end{array}$ & M.S.B. & $1.65 \mathrm{~kg}$ \\
\hline $\begin{array}{l}\text { Reduced fetal } \\
\text { movements }\end{array}$ & $\begin{array}{l}\text { Yes, consulted } \\
\text { herbalist }\end{array}$ & 1 & Abruptio & M.S.B. & $1.4 \mathrm{~kg}$ \\
\hline $\begin{array}{l}\text { Swelling of feet } \\
\text { and legs }\end{array}$ & $\begin{array}{l}\text { No (lamily took } \\
\text { action with fit) }\end{array}$ & 1 & Eclampsia & S.B. & $1.4 \mathrm{~kg}$ \\
\hline $\begin{array}{l}\text { Previous } \\
\text { Caesarean section }\end{array}$ & $\begin{array}{l}\text { No, thought church } \\
\text { affiliate (Zionist) }\end{array}$ & 1 & None & NVD - live infant & $3,3 \mathbf{~ k g}$ \\
\hline $\begin{array}{l}\text { Rupture of } \\
\text { membranee }\end{array}$ & Yes & 1 & $\begin{array}{l}\text { Intra-uterine } \\
\text { infection } \mathrm{C} / \mathrm{S} \text { done }\end{array}$ & NVD - live infant & $2,2 \mathrm{~kg}$ \\
\hline $\begin{array}{l}\text { None - had pain } \\
\text { at onset of labour }\end{array}$ & None & 2 & None & $\begin{array}{l}\text { NVD - live infant } \\
\text { NVD - live infant }\end{array}$ & $\begin{array}{l}2,3 \mathrm{~kg} \\
2,9 \mathrm{~kg}\end{array}$ \\
\hline $\begin{array}{l}\text { Headache and } \\
\text { epigastric pain }\end{array}$ & $\begin{array}{l}\text { None identified until } \\
\text { informant had a fit }\end{array}$ & 1 & Eclampsia & C/S - live infant & $2,1 \mathrm{~kg}$ \\
\hline None & $\begin{array}{l}\text { identified until } \\
\text { informant had a fit }\end{array}$ & 1 & Eclampsia & $\begin{array}{l}\text { NVD - live infant } \\
\text { NND }\end{array}$ & $2,1 \mathrm{~kg}$ \\
\hline
\end{tabular}

ABBREVIATIONS

\begin{tabular}{|l|l|}
\hline C/S & Caesarean section \\
\hline NND & Normal neonatal death \\
\hline NVD & Normal vertex delivery \\
\hline MSB & Macerated stillbirth \\
\hline SB & Stillbirth \\
\hline
\end{tabular}

\section{$\cos T$}

Six informants considered antenatal care charges expensive. One informant said " $R 20,00$ is expensive but what can I do, it is better than losing a job." According to Rosenstock in Mikhail (1981) a perceived threat such as loss of employment was much more serious than perceived cost of paying $R 20,00$ per visit to the private doctor. The patients who had small families and lived above the HSL and HEL had considered antenatal fees affordable, yet other factors, such as fear of losing the job, out-weighed perceived cost and they therefore remained unbooked until an emergency situation occurred.

\section{TRANSPORT}

Although transport was easily available for respondents during regular hours it was inaccessible during an emergency and after hours.

\section{TELEPIIONE}

The absence of a telephone service for seven patients rendered the clinic service inaccessible. Two patients who had access to the telephone during regular hours could not use it at night or during emergency if the house owner was not available.

\section{KNOWLEDGE OF TIIE SIGNS OF ONSET OF LABOUR}

All respondents recognised lower abdominal pain as a relevant sign. Only three respondents recognised show and ruplure of membranes as signs of onset of labour. Other signs mentioned were frequent micturition, restlessness and vomiting. It appeared that most respondents considered onset of labour from the time when contractions became very strong towards the end of the first stage.

\section{PREGNANCY OUTCOME}

Maternal complications of importance noted in the study included abruptio placentae, eclampsia and early rupture of membranes. Fetal outcome influenced by maternal health included low birth weight (LBW) infants, stillbirths (SB) and neonatal death (NND).

Two patients had normal well grown infants. Eight patients had LBW infants.

\section{LIMITATIONS OF THE STUDY}

The sample was small and as such, generalisation could not be made. The time factor was limited and the researcher could not interview as many women as she would have liked. Clients who lived in unnamed and unnumbered streets and houses in informal settlements were difficult to follow up. This limited the number of respondents who were visited in their homes and some clients from far-off rural areas could not be followed up after they had been discharged from hospital. The study was done on those who delivered in hospital. Women's intentions on future utilisation of health services were not asked from all of the clients. Low birth weight babies were not examined to see if they were growth retarded or premature, or both

\section{CONCLUSION AND RECOMMENDATIONS}

Emanating from the results of the study th following conclusions are pertinent.

Instability is the dominant feature in the cases studied. Both urban and rural dwellers are, for one reason or another, exposed to accommodation, employment and financial instability. Those who have accommodation in the urban areas live in informal settlements which are easily demolished and pose a high population mobility problem. Those who live in rural areas have suffered from lack of effective health services. Both urban and rural dwellers alike have suffered distuption of health services.

Health service failure as demonstrated by the inability to attend health services and negative attitudes of health personnel, indicate a health service which has failed to come to terms with the rapidity of change within the rapidly changing nature of South African sociely.

Socio-cultural constraints resulting in a teenager not attending clinic for fear of being identified by family members and friends poses a challenge to health planners and medical anthropologists. Information received by carrying out a home visit enriched the study as some of the information had not been exposed in hospital.

For all these reasons it is recommended that the approach to health education for child-bearing women be de-Westernised and made appropriate for the wider community, including 
the informal health workers who are highly utilised by the pregnant women.

Intensified health education is indicated with regard to signs of onset of labour and danger signs during pregnancy. Pregnant women must be given information to allow them to identify obstetrically significant danger signs.

Available health services must be made effective by unification, coordination, integration and standardisation of matemity records.

Antenatal clinic must be offered at hours when it will be accessible to the patient.

Decisional control on the part of the health professionals should be moderated to allow for open communication and client decision-making where emotional issues apply.

Communication with the client treated for an obstetrical emergency needs to be appraised so that patients transferred from one institution to the other are given information about the indications for such transfer.

Improvement of the employer/employee relationship to generate a mutual trust relationship and ensure job tenure would add to the client's sense of security.

\section{BIBLIOGRAPIIY}

DEMUWAGUN, Z.A. (1972). Major impediments to effective use of public health services lth Educ.J. 31:21-27.

CONCO, N.Z. (1972). The African Bantu Traditional Practice of Medicine : Some preliminary observations. Social Science and Medicine. 6:283-322.

COX, C.L. (1982). An interaction model of client health behaviour: Theoretical prescription for nursing. Advances in nursing science:31-55.
DOKE, C.M. AND VILAKAZI, B.W. (1972). Zulu-English Dictionary. Johannesburg: Witwatersrand University Press.

GALWAY, K. WOLF, B. AND STURGIS, R. (1987). Child survival : risks and road to health. Columbia: Westinghouse.

GREEN-THOMPSON, R. (1990). Personal Communication.

HAMILTON, R.A. PERLMAN, T. AND DE SOUZA, J.J.L. (1987). The unbooked patient Part 1 Reasons for failure to attend antenatal cinics. S. Afr. Med. J. 71:28-31.

HAMILTON, R.A. PERLMAN, T. AND DE SOUZA, J.J.L. (1987). The unbooked patient Part II Outcome of pregnancy in unbooked Coloured patients. S. Afr. Med. J. 71:31-34.

INSTITUTE OF RACE RELATIONS (1990). Personal Communication.

LARSEN, J.V. (1978). Consumer opinion on clinic services in a rural area. S. Afr. Med J. 53:827-828.

LARSEN, J.V. AND VAN MIDDELKOOP, A. (1982). The unbooked mother at King Edward VIII Hospital: Durban. S. Afr. Med J. 62:483-486.

LOENING, W.E.K. AND BROUGHTON, M. (1985). The unbooked patient - why does she not book? Proceedings of the fourth conference on priorities in perinatal care in South Africa Johannesburg: University of the Witwatersrand: $31-33$.

MABASO, M.S. (1988) : An evaluation of total health care given to black babies with profound congenital defects. Unpublished thesis for M.Soc.Sc. Durban: University of Natal
MCDONALD, T.P. AND COBURN, A.F. (1988). Predictors of prenatal care utilisation. Soc.Sc. Med. 27(2), 167-171.

MIKHAIL, B. (1981). The health belief model: $A$ review and critical evaluation of the model, research and practice. Advances in Nursing Science 65-79.

PATTISON, A. AND ROSSOUW, L. (1985). A prospective controlled study of the unbooked mothers at Tygerberg Hospital. Proceedings of the fourth conference on priorities in perinatal care in South Africa. Johannesburg: University of the Witwatersrand, 34-37.

RYAN, J.G. SWEENEY, PJ. AND SOLOLA, A.S. (1980). Prenatal care and pregnancy outcome. Am. J. Obstet. Gynaecol 137 (8);876-881.

SCOTT-SAMUEL, A. (1980). Why don't they want our health services? The Lancer 412-415.

SITHOLE, C. (1990). Personal Communication.

ST CLAIR, P.A. SMERIGLIIO, V.L. ALEXANDER, AND C.S. CELENTANO, D.D.(1989). Social network structure and prenatal care utilization. Med Care 27 (8):823-832.

Rhosta Gcabo
M.Soc.Sc. RN RM RCHN RNA DCCAI Diplo-
ma Advanced Mid
Neonatal Nursing Science
University of Natal, Durban
Heidi B. Broakes
M.Soc.Sc. RN RM RP RHV DNE
Department of Nursing
University of Natal, Durban

